\title{
The Way to the Diversification of Macau's Social Economy: a Study on Macau's Cultural Tourism Development
}

\author{
Li Xi and Cheng Si Wei
}

\begin{abstract}
Macau is known for its developed Casino industry. In 2007, the revenue from the Gaming industry for the first time surpassed Las Vegas and Macau became the top Gaming City in the world. Although Macau benefited a lot from the gaming industry, its monopoly status in the social economics became one of the unstable factors to the sustainable development of Macau. Diversification is obviously important when Macau encountered financial crisis and a tough policy on the Mainland residences' visit to Macau. At the same time, Macau won the award of World Culture Heritage for its historical and cultural district in 2005, the World Culture Heritage Sites added new factors to the local attractions. Based on the past studies, the culture tourism is a very important sector in the tourism market; it stands for one of the future trends in the tourism development. To the regional development, the culture tourism can lead to economic promotion, culture upgrade and image-rebuilding. It can also promote the development of economic diversification, creating diversified development mode, and optimizing the visitor structure. Obviously, developed culture tourism can be one of the triggers to a better image, more versatile attractions and a sustainable Macau. The development status of the culture tourism in Macau should be defined both from the angle of tourists' experience and the angle of the economics. The purpose of this research is to test the effects of the World Culture Heritage sites on diversification of Macau's local economy, analyzing the feasibility of taking culture tourism as a chance to promote the diversification of Macau's tourism economy. The methods that were used during the research include the survey, observation and literature analysis. A total 300 questionnaires were distributed, where 215 questionnaires were successfully completed during the survey. At the same time, observation on the behavior of the tourist was carried out. On the basis of the information acquired from the survey and observation, the development status of the Macau culture tourism was described and further suggestion on the diversification of the Macau's industry were provided.
\end{abstract}

Index Terms-Culture Tourism, Industry Diversification, Macau.

\section{INTRODUCTION}

\section{A. The dilemma of Macau's development}

1) The pillar-typed economic structure

Macau is known for its developed Casino industry. In 2007, the revenue from the Gaming industry for the first time

Correspondence:Dr. Li Xi, Faculty of International Tourism, Macau University of Science and Technology, Taipa, Macau , Email: Xli@must.edu.mo surpassed Las Vegas and Macau became the top Gaming City in the world. Although Macau benefited a lot from the gaming industry, its monopoly status in the social economics became one of the unstable factors to the sustainable development of Macau. With the open-up policy carried out, more and more transnational corporation came to Macau, and there is a high concentration of the resources in gaming industry. For example, more than half of the residence in Macau are employed in gaming related industries and the tax from the gaming industry stands for the $82 \%$ of the government revenue in 2008. The local economy's heavy relying on gaming industry increase the vulnerability. Though, the local government wants to turn the mono-typed economics into a more diversifying one, the percentage of the tax from gaming industry of the total tax revenue keeps increasing, in 2006 the percentage is $54 \%$, in 2007 is $63 \%$, while in 2008, the percentage rises to $82 \%$. Accordingly, when financial crisis arrived in 2008 , there was a earthquake in the society, over 10000 foreign labors were fired at one night and some of the local residence were at the risk of unemployment.

2) The changing development environment

Nowadays, Macau is encountering environmental changing. There are three trends that can not be neglected.

First of all, Mainland China is tightening up "Self-organized traveling" policy. Since the majority of tourists are from China Mainland, the policy will no doubt have negative effects on the demand sector in the market, especially the tourists from the metropolis in China Mainland.

Secondly, there are direct flights between Taiwan and Mainland China. In the past, Macau has played a very important role on the communication between Mainland and Taiwan; for those came from Taiwan, Macau is a transportation node to the Mainland China. Some experts also said that with the conduct of cross-strait direct flights, the declination of the number of Taiwan visitors to Mainland from Macau airport is foreseeable. The statistics show that the visitors from Taiwan to Macau by air in September 2008 decreased by $16.81 \%$ when compared with the same period in 2007. At the same time, the arrival of visitors from Taiwan by air decreased by $8.34 \%$ from January to September of 2008 than the same period in 2007.

Thirdly, the impact of the Global Financial Crisis still exists. Due to the recession of the global macro-economy in 2008 and 2009, the consuming and investment confidence was constrained. Meanwhile, the surrounding countries or 
regions are developing or considering the feasibility of Gaming industry, such as Singapore and Taiwan. The compressing market will lead to fierce competition.

3) The inner challenge of Macau's society and economics

Macau is a typical micro-economy, the land and other resources are more or less limited. Recent years, the booming of gambling tourism industry brought substantial economic benefits. Since 2004, the average annual growth rate of Macau's gambling industry reaches $60-70 \%$. At the same time, the development of gambling has brought heavy pressure and burden for the local social development, the problems such as labor shortage, traffic congestion, the high property price have became the focus of the society.

TABLE 1 INDICATORS OF SOCIO-ECONOMICS FROM 2004 TO SEPTEMBER 2008 IN MACAU

\begin{tabular}{|c|c|c|c|}
\hline & The number of crime & Food price index & The type of housing and fuel price index \\
\hline 2004 & 9,786 & 99.38 & 100.16 \\
\hline 2005 & 10,538 & 103.34 & 108.57 \\
\hline 2006 & 10,855 & 107.18 & 121.33 \\
\hline 2007 & 12,921 & 115.96 & 132.92 \\
\hline September 2008 & $8,154^{*}$ & 139.12 & 145.69 \\
\hline
\end{tabular}

Source: Macau Statistics and Census Service.

Table 1 shows the past five years, the changes of part of the social and economic indicators in Macau, in which the number of crimes are rising more rapidly, for example, the number of crime case was 7402 over the same period (1-7 months) in 2007 and an increase of $10.16 \%$ in 2008 . The prices of the consumer goods (food) and housing continued rapid rising, which cause tremendous pressure to the social development of Macau.

In addition, the quality of the Macau tourism industry needs to be improved. Through a comparison between Macau and Hong Kong in the indicators of quality of tourism development, we can find that the consumption of visitors to Macau was 1637 MOP per capita in 2007, while visitors to Hong Kong spend about 4799 Hong Kong dollars per capita in 2006. When it comes to the period of stay, the average stay in Macau is relatively short with a period of 1.1 days; while overnight visitors stay an average of 1.6 days. For Macau's future development, there is a great need of increasing the consumption level and stay period of the visitors.

To sum up, Macau now is confronted with challenges from all sides, but from another viewpoint, we can say that Macau is now facing the best opportunity of depth adjustment. What Macau needs is to conduct a careful planning for the future, or in another word, find a way to a versatile industry structure and a higher competitiveness of tourism.

\section{B. Culture tourism and the city development}

Tourism is a culture-based industry; the tourism products without cultural connotation will have no long-term vitality and appeal. The three major trends of Tourism in the $21 \mathrm{st}$ century are: cultural tourism, eco-tourism and leisure tourism. The so called culture tourism referred to a type of special interest tourism involving leisure travel for the purpose of viewing or experiencing the distinctive character of a place, its peoples, and its products. The typical culture tourism includes the visits to UNESCO World Heritage Sites, visits to the historic cities, architectural sites, cathedrals and battlefields. Some of the scholars pointed out that the culture tourism is a all-inclusive visiting. It is the region's culture attracts the visitors to explore and experience, specifically the lifestyle and the history of the people in those areas, their art, architecture, religion(s) and all elements that shaped their way of life.
Besides acting as the core of the tourism industry, culture tourism can play an important role in regional development in different world regions. (OECD, 2009)

First of all, Cultural Heritage Tourism can help promote the city's economic development. This effect was caused by the comprehensive contents and the multiplier effect of the culture tourism. Especially the world culture heritage sites can attract tourists of all ages and leads a relatively high tourism revenue.

Secondly, the culture tourism can help remold the image of the city and upgrade its social culture. Cultural heritage of the city can highlight the traditional culture of the city as the most typical tourism resource. By this means, local culture was exposed to the tourists and well preserved. With the development of the heritage tourism, more and more new elements will be mixed into the culture heritage and thus cause the further culture upgrading.

Although in some places cultural tourism has led to the transformation of physical settings, environmental degradation, soaring land prices, and reduced access to the land for indigenous peoples. Cultural tourism is still one of the powerful tools to ensure the economic development and expansion of the industry chain.

Macau won the award of World Culture Heritage for its historical and cultural district in 2005, the World Culture Heritage Sites added new factors to the local attractions. How much can Macau's tourism and local economics benefits from world culture heritage sites and by what means can the newly developed culture tourism contribute to the diversification of the industry? The question can not be answered at present; however we can look deep into the development of culture tourism to test its economic benefits and find out some strategies to better combined the culture tourism and local economics.

\section{Methodology}

Through the literature review, we realized that culture tourism is one of the effective ways to stimulate the local economics and help update the industry structure. To Macau, what we are most interested in is to evaluate the values that world culture heritage brought to local tourism and find out 
the strategies to promote the diversification of the present one-polar-typed economic development model. When develop the culture tourism, there are lots of benefit-related parties in the culture tourism development, such as tourists, tourism promoters, and locals. In the past research on the related topics, empirical study and survey on the tourists were two of the most frequently used methods. (Sun Li ping et al. 2005) When it comes to Macau culture tourism, Liang zheng ning et al.(1999), Xie Zheng Xi et al.(2001), Aliana et al.(2007) claimed that culture tourism can push Macau forward by offering opportunity of different experience besides gambling. During the research, a survey on the tourists was carried out to test the world culture heritage sites' effect on tourists' perception. In addition, the research tries to find the factors that need to be improved in the culture tourism in Macau in order to enhance the economic impact of culture tourism.

The questionnaire with five groups of questions was accomplished during a one-week period in the middle of April of 2008 after a pilot test in March 2008. On the basis of the previous researches in culture tourism, the survey instrument was developed and protested in March 2008, using a pilot test on 30 tourists random selected at the Border Gate. The pilot test on the questionnaire requires some minor revisions on the expression and choices provided in the questionnaires. These pilot tests were excluded from the final survey. The final survey instrument includes the following questions: (1) Three tourists behavior related questions (purpose, accompany, itinerary arrangement); (2) Two World Culture Heritage Tourism awareness related questions (awareness level, information channels); (3) Three questions on the satisfaction of the tourists about the world culture heritage tourism in Macau; (4) Open-ended questions to further elaborate on the development of diversification industry and views about the world heritage tourism; (5) two questions on the suggestions of the direction of the development of diversification industry in Macau based on the world cultural heritage in Macau.

Data obtained from the survey were analyzed by SPSS 13.0, they suggest that most of the tourists do not get much effective information before they come to Macau and the fame of the world culture heritage in Macau is not so obvious The high concentration of the visit willingness on $35 \%$ of the heritage sites demonstrates that the development of the world culture heritage tourism in Macau is in status of uneven. The author conducted a survey through the method of the random sampling in the new road in Macau, Macau Ferry Terminal, and Ruins of St. Paul on April 12-19 in 2008. The survey involved a total of 300 travelers and the usable questionnaires are 215 , the recovery rate of the questionnaire was $71.66 \%$.

A total 300 questionnaires were distributed, where 215 surveys were successfully completed, the percentage of the valid questionnaires is $71.66 \%$. Considering the average time that tourist stays in Macau is only 1.1 day, most of the tourists are in such a hurry to pay a visit, a high rejection rate of $28.34 \%$ is acceptable.

\section{FINDINGS}

A. The world culture heritage sites have positive effects on the perception image of visitors to Macau

The mean of the awareness of the world heritage in Macau is 2.33 , where the maximum is 5 (know the world culture heritage tourism in Macau well), reveals the rating of the tourists' awareness is below average level and the fame of the world culture heritage in Macau is not so outstanding. Majority of the visitors only once heard of it but know very few about it. However, the world culture heritage has changed the destination image of the visitors to Macau. According to the survey, only $8 \%$ of the visitors said that they never heard of Macau's world culture heritage, and among those visitors came for sightseeing only $3 \%$ never heard of world culture heritage in Macau. We can say that world culture heritage sites have added some new elements to the traditional Casino City and they have changed the perception image of more and more visitors to Macau. From this point of view, the world culture heritage sites in Macau can be a trigger to the destination image changing.

\section{B. The economic benefits were subjected to the satisfaction level of the visitors}

People will tend to increase their consumption when they are satisfied with the service. Through the survey we find out that some service factors needs to be improved to increase the satisfaction level of the tourists and then in turn increase their desire for consumption in Macau's world culture heritage sites. $12 \%$ of the visitors believe that Macau's public transport needs to be improved. It was repoted that during 2004-2007, the number of Japanese tourists increased in more than doubled, but because of the constraints on Macau's tourism resources and low efficiency of transportation and border gate operation, it was difficult to attract Japanese visitors to stay longer in Macau. By testing the anticipation of the visitors, we can also found out that what we provided to tourist in world culture heritage sites can not meet the needs of the visitors. For example, through the survey, about $55.9 \%$ of the visitors expect folk culture shows at the sites, and $42.8 \%$ of the visitors hope the culture heritage sites can exhibit the living scene of Macau. About $56.3 \%$ of the visitors more like to participate in an interactive program than just walking and sightseeing. If only the needs of the visitors are met, the attraction and economic effects can be predictable. In order to increase the status of the culture tourism in Macau's tourism industry, we should try to increase the economic benefits through the enhancement of the service and the facilities.

\section{Culture tourism can be a chance to the diversification of the future development}

Culture tourism has grown into one of the most important tourism products in Macau since 2005. With the development of culture tourism, there are more attractions than casinos for the visitors in Macau. According to the data from the survey, about $67 \%$ of the tourists will surely recommend the culture heritage sites to their friends or families. And about $24.3 \%$ of the visitors feel satisfied with the culture tourism products in Macau. It is a very outstanding achievement taking the 
development starts from 2006. From the viewpoint of industry diversification, culture tourism can be a chance, but there are lots of steps before we reach the final goal. Such as the optimization of the product and service and increase the direct revenues form the culture tourism. Investors are profit-driven, where there is profit there will be a new industry. We believe that when Macau is in such a dilemma, the culture tourism can be the hope, if we can scientifically organize the resource in the society and all the interest related parties to participate into the culture tourism development.

\section{SugGestions}

From the above analysis we know that the world culture heritage tourism has a positive effect on the diversification of the Macau industry. However some steps should be taken to increase the quality and impact of the culture tourism to the local economics. According to the findings through the survey, the following suggestions have been provided.

\section{A. Using the strategy-oriented ideas to guide the cultural tourism development}

Strategy-oriented thinking is one of the important ideas of tourism development. From the survey we can see the image of gambling is also being affected by the awareness of tourist on the World Heritage to Macau in a large extent. The construction of the world cultural heritage tourism products of Macau at least need go through three steps, namely the building of the initial brand, the development of the product chain, the enhancement of brand image.

The survey data shows that $85.1 \%$ of visitors have a certain understanding to the world cultural heritage in Macau before they come. It can be regarded that the initially building of the brand of Macau's World Heritage tourism is successful. For the future development, a sub-regional development model should be used. The sub-regional development model refers to dividing the heritages into several areas and according to their functions and characteristics, when developing, we should respect their personality.

\section{B. Upgrading the services and facilities of the cultural tourism}

The upgrading of the services and facilities are mainly embodied by the information technology. The information services are an important prerequisite for the satisfaction of today's tourists. When Macau develops the world cultural heritage sites, it should constantly updated the map of cultural heritage sites, the presentations and the opening hours, but also need to use the IT technology to strengthen the effectiveness of information transmission. The author proposes to co-operate with the Macau tele-communications companies, using the technology of the community broadcast to publish the real-time information of the cultural heritage sites by via mobile phones in order to guide the tourists to visit the World Heritage sites. Within the scenic spots, you can make use of the multimedia technology, or self-guided machines and other facilities to help the tourist to understand the Macau's tourism cultural, and offer a better environment for the tourists.

\section{C. systematically develop the culture product chain}

As the tourists in Macau have greater differences in the needs of cultural heritage tourism, we should build out the multi-functional and three-dimensional product system for the different tourists. For the general tourists, we can develop and recommend the landmark attractions. For the visitors chasing a better understanding the culture of Macau, we should provide the products of in-depth experience, such as through the interpretations of the cultural activities or the participation of tourists to help them to experience the traditional culture. In addition, among the World cultural Heritage in Macau, there are many arts, folklore and the classical elements of buildings, which can be integrated to fit the needs of the specialized research-based tourists.

\section{Carring out extensive cooperation with interest-related parties}

when designing the marketing plan, we'd better take the government, tourist attractions, hotels and other service sectors into consideration and encourage them to help each other.

We can try to keep visitors focusing on Macau's culture tourism through the co-operation between the government, hotels, tourism attractions and the communication and feedback of information. As Figure 1 shows: Because the hotel has the highest efficiency on touching the visitors, it can act as a media for the visitors to know and visit world culture heritage. During the cooperation, the government agencies provides the brochures, TV programs and information of incentives, meanwhile the hotels take the charge of passing the information, TV programs to the tourists and cooperating with tourist attractions, such as provide the shuttle bus between the culture sites and hotels. The wide exposure of information can arouse the visitor's interest, even it is unable to participate in this trip, but sometime later they will make a trip plan to the world culture heritage in Macau.

Figure 1: the picture of the transmission and promotion of tourism information after the visitors come to Macau. 


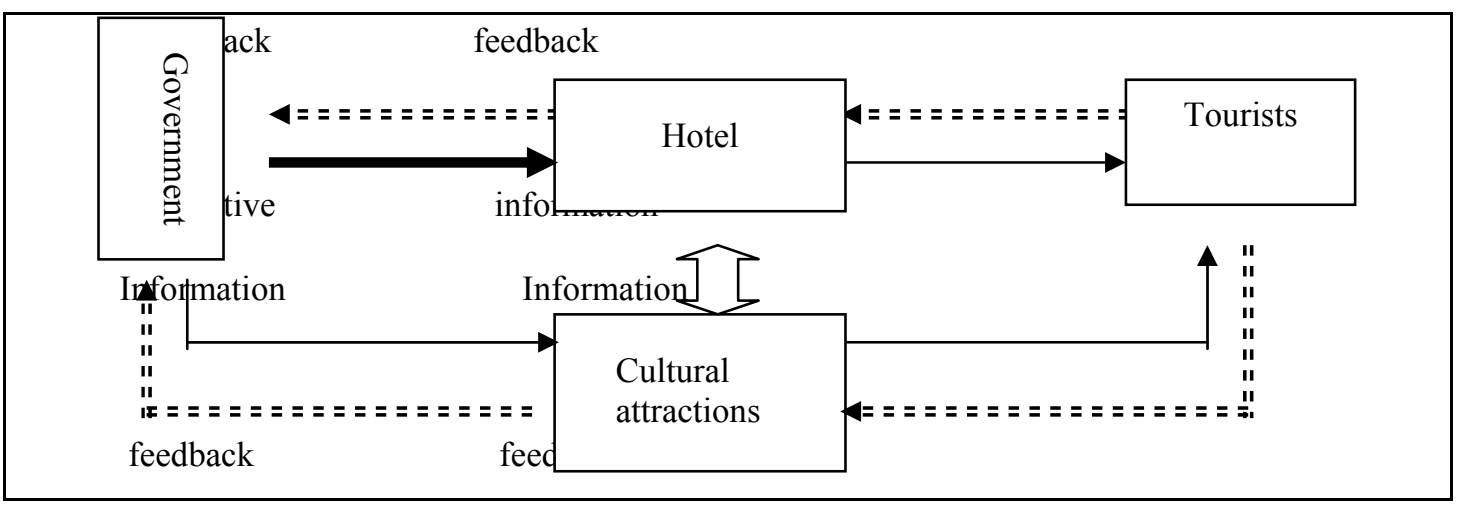

Macau can also design a plan to attract more tourists to visit the world cultural heritage by increasing the connections between cultural tourism and the gambling industry to some extent. That is to say we can use the effect of gambling industry to promote the development of the heritage tourism.

Cultural tourism can carry out the extensive cooperation with the exhibition industry. In the reception of the exhibition industry, Macau should do a good job of the reception service to tourists, when they arrive in Macau and attended the meeting, the conference organizers should vigorous advocate Macau's cultural and tourism in the exhibitors manual, such as the organizer can print the Macau's well-known cultural tourism attractions on the cover or inside pages in the Manual, which maybe stimulate their interest after the meeting and at the same time, they also should intensify its advocacy efforts on the participants' families.

\section{CONCLUSION}

With the study refers to explore the diversification development path of Macau, it has a certain degree of feasibility from the perspective of cultural tourism. Cultural tourism is the valuable wealth in the diversification development, and it is also one of the important channels of in-depth experiencing Macau's cultural. Many of the world's important cultural tourism attractions have become the high-profile tourist attractions. The development of cultural tourism can be regarded not only as a complement to urban development, but also an effective way to promote the city. Now Macau is on its way to a more diverse society besides casinos. With no doubt, the culture heritage can play an important role, but the relatively humble economic benefits and low satisfaction level prevent it been linked with the trigger to a diverse society. We believe that through innovative development and extensive cooperation with the interest-related parties, the positive impact of the world culture heritage tourism can be significant and Macau will benefit a lot from it.

\section{REFERENCES}

[1] Anastasopoulos, P. (1992). Tourism and attitude change: Greek tourists visiting turkey. Annals of Tourism Research, 19, 629-629.

[2] Bao Ji Gang, \& Chu Yi Fang. (1999). Tourism Geography. Beijing: Higher Education Press.

[3] Boerwinkel, H. (1995). Management of recreation and tourist behaviour at different spatial levels. Tourism and Spatial Transformations,
[4] Clawson, M., \& Knetsch, J. L. (1966). Economics of outdoor recreation.

[5] Cooper, D. R., \& Schindler, P. S. (1998). Business research methods Irwin/McGraw-Hill Boston.

[6] Crompton, J. L. (1979). An assessment of the image of mexico as a vacation destination and the influence of geographical location upon that image. Journal of Travel Research, 17(4), 18-23.

[7] Cheng wei feng, the research of the reality of experience on heritage tourism and creation way, Journal of Guilin Institute of Tourism, 2008

[8] Echtner, C., \& Ritchie, B. (2003). The meaning and measurement of destination image. Journal of Tourism Studies, 14(1), 37-48.

[9] Fesenmaier, D., \& MacKay, K. (1996). Deconstructing destination image construction. Tourism Review, 51(2), 37-43.

[10] Gartner, W. C. (1993). Image formation process. Communication and Channel Systems in Tourism Marketing, 2(2/3), 191-215.

[11] Yang li dan, the research process of heritage tourism in China, Beijing international studies university, 2007

[12] Stabler, MJ. (1988). The image of destination regions: Theoretical and empirical aspects. Marketing in the Tourism Industry, , 133-161.

[13] van der Borg, J., Costa, P., \& Gotti, G. (1996). Tourism in european heritage cities. Annals of Tourism Research, 23(2), 306-321.

[14] Wang li hua, service management, Beijing: China Tourism Press, 2007

[15] "Cultural Tourism." International Encyclopedia of the Social Sciences. Thomson Gale. 2008. Retrieved December 27, 2009 from Encyclopedia.com: http://www.encyclopedia.com/doc/1G2-3045300502.html

[16] OECD (2009) The Impact of Culture on Tourism. OECD, Paris 